\title{
Os direitos dos professores cate- draticos do Curso de Doutorado
}

Waldemar Ferreira

1. Suscitou-se, no relatorio do movimento academico e administrativo da Faculdade de Direito, no ano de 1936, interessante questão: a de saber se os professores catedraticos do Curso de Doutorado, nomeados pelo Governo do Estado, são vitalicios, ou não. Pareceu ao eminentissimo Diretor da Faculdade de Direito que não. Como os argumentos em prol de sua tése tiveram publicidade nesta revista e se fez, no relatorio, referencia nominal ao professor, cujo direito se contestou, cabe-lhe o direito de defendel-o. Antes, porém, de expender as razões que em seu bem militam, urge ressaltar, em sua inteireza, circunstancias não bem apreeendidas, nem bem expostas, naquelle documento.

2. Foi a questão posta em debate por efeito de um oficio, que o autor deste artigo endereçou ao sr. Secretario da Educação e Saude Publica. Deu dele noticia o relatorio nestes termos:

“ O Professor Waldemar Ferreira, cuja situação é identica á dos outros nomeados, pretendia que, sem embargo da supressão, perdurassem seus direitos aos vencimentos e outras vantagens do cargo, por consequencia dos atributos de vitaliciedade e inamovibilidade com que se imaginava investido nas funções. Assim pretendendo e, ao mesmo tempo, reconhecendo não fazer jus de fato aos salarios da cátedra enquanto deputado federal, su- 
geria, em requerimento ao Secretario da Educação, fosse posto em disponibilidade não remunerada, sem prejuizo dos demais direitos"

Não teve o Professor Francisco Morato, quando isso escreveu, diante dos olhos a representação do Professor Waldemar Ferreira, a que aludiu, atribuindo-lhe considerações, que ele não fez e não podia fazer. Resultou da infedelidade de sua memoria, sempre tão precisa, mas no momento claudicante, aquele topico, que está a reclamar uma retificação.

Eis o oficio:

“São Paulo, 4 de fevereiro de 1936. - Exmo. Sr. Dr. Secretario,

"Nomeado, por decreto de 8 de junho de 1934, para reger, de acôrdo com o art. 14 do dec. n. 6.429, de 9 de maio de 1934, a cadeira de Historia do Direito Nacional, do Curso de Doutorado da Faculdade de Direito da Universidade de São Paulo, dela me empossei em 12 de junho de 1934, passando a auferir, nos termos daquele decreto, os vencimentos, que me competiam, correspondentes a dois terços dos que percebo como professor catedratico de Direito Comercial do Curso de Bacharelado.

"Tendo a lei n. 114, de 11 de novembro de 1935, tornado facultativa nas Faculdades de Direito, oficiais ou reconhecidas, a existencia do Curso de Doutorado, houve por acertado suprimi-lo a Egregia Congregação da Faculdade de Direito da Universidade de São Paulo, a começar do ano letivo prestes a iniciar-se.

"Estou, em virtude dessa deliberação, privado da regencia de minha catedra do Curso de Doutorado. 
"Declarado, pelo art. 49 do dec. n. 6.429, de 9 de março de 1934, professor vitalicio e inamovivel desde a posse - principio que se reproduziu no art. 46 do dec. n. 7.068 , de 6 de abril de $1935-$ evidente é que, privado de reger a minha catedra, conservo, não obstante, os direitos e vantagens resultantes da minha investidura vitalicia.

"Tendo, no entanto, como deputado federal por São Paulo, contribuido, com o meu voto, para a aprovação do projeto, convertido na lei n. 114, que tornou facultativa a existencia do Curso de Bacharelado - julgo-me no dever de não continuar a perceber os vencimentos, a que me assistem direitos por terem ficado suspensos os meus labores de professor catedratico de Historia do Direito Nacional.

“Expondo a v. exa. este estado de consciencia, permito-me sugerir a conveniencia de, por decreto, ser posto em disponibilidade não remunerada, mas sem prejuizo de quaisquer outros direitos, de modo que, restaurando-se, a qualquer tempo, o Curso de Doutorado, restaurados tambem sejam os meus vencimentos, com todas as vantagens e proventos até então e de futuro accrescidos. Sendo permitido á Douta Congregação da Faculdade de Direito da Universidade de São Paulo restaurar, se e quando julgar conveniente, o Curso de Doutorado, protesto voltar á regencia de cadeira, de que continúo sendo titular, deixando ressalvados os meus direitos, para que duvida não haja.

"Valho-me do ensejo para reiterar a v. exa., Exmo. Sr. Secretario, os protestos de minha estima e mais alta consideração.

“A sua exa. o Dr. Cantidio de Moura Campos, Secretario da Educação e da Saude Publica. Waldemar Ferreira". 
Não pretendia o sinatario desse oficio "perdurassem seus direitos aos vencimentos", nem reconheceu "não fazer jus de fato aos salarios da catedra enquanto deputado federal", como se lê á pag. 28 desta revista, vol. XXXIII, fasc. I. Bem ao contrario disso, comunicou ele ao Governo que não receberia os seus vencimentos, enquanto não se restaurasse o Curso de Doutorado. Deixou, efetivamente, de os perceber. Sabia, de outro lado, que, nos termos do art. 33, paragr. 3, da Constituição Federal, durante as sessões da Camara dos Deputados, só receberia dos cofres publicos ajuda de custo e subsidio, "sem outro qualquer provento do posto ou cargo que ocupe"

$\mathrm{O}$ que, portanto, no relatorio se exarou, muito distanciado está da verdade. Reclamava uma corrigenda. Ela aqui fica, para que se não formulem juizos erronios.

3. Instituido o Curso de Doutorado, o dec. n. 19.852, de 11 de abril de 1931, art. 34, determinou fossem os professores das materias, que o compunham, designados pela Congregação dentre os professores catedraticos do Curso de Bacharelado. Seriam os professores deste os daquele.

Transferida a Faculdade de Direito de São Paulo, pelo dec. n. 24.102, de 10 de abril de 1934, para o Estado de São Paulo, afim de incorporar-se á sua Universidade, passou ela a ser regulamentada pelas leis estaduais.

4. Deu-lhe regulamento, com efeito, o dec. n. 6.429, de 9 de maio de 1934. Teve ele o intuito de tornar efetivos os professores do Curso de Doutorado; e, por isso, prescreveu, mui categoricamente, no art. 14, que, "nas cadeiras do Curso de Doutorado, que estiverem vagas, serão providos os professores catedraticos do Curso de Bacharelado, que a Congregação, por dois terços de votos, designar"

Cuidando de dar provimento ás cadeiras, que então vagas se achavam, a Congregação, pelo modo estipulado, designou os professores catedraticos do Curso de Bacharelado, entre os quais o Dr. J. J. Cardozo de Mfllo Neto, para a 
de Ciencia das Finanças, e o Dr. Waldemar Ferreira para a de Historia do Direito Nacional. Feita a designação, nomeouos o Governo do Estado, foram eles empossados, entrando em exercicio de seus cargos e inscrevendo-se no funcionalismo estadual.

Não bastou, portanto, a simples designação da Congregação para que - como no regime da lei federal - entrassem os professores na posse de suas cadeiras do Curso de Doutorado; foram nomeados, todos eles, por decreto do Governo do Estado.

Este é pormenor de alta relevancia.

5. Pretendeu o dec. n. 6.429, de 9 de maio de 1934 , sem duvida, dar provimento efetivo e definitivo ás cadeiras do Curso de Doutorado. Previu, por isso, a hipotese da Congregação não fazer a designação, pela fórma constante do art. 14. Prevendo-a, acrescentou, no art. 15, que as cadeiras do Curso de Doutorado, para as quais a Congregação não fizesse a designação prevista no artigo anterior, seriam “providas na fórma do art. 66 e seguintes, e aos respetivos professores competirão vencimentos integrais". Nos arts. 66 e seguintes, traçou o regulamento as normas para o concurso de catedraticos do Curso de Bacharelado.

Teria o Curso de Doutorado, dessarte, duas categorias de professores catedraticos: a) os designados, de entre os professores catedraticos do Curso de Bacharelado, por dois terços dos votos da Congregação; $b$ ) os que, não sendo professores daquele Curso, se submetessem a concurso, e, classificados em primeiro lugar, fossem nomeados pelo Governo do Estado.

Os professores catedraticos do Curso do Bacharelado, nomeados para o Curso de Doutorado, acumulariam o exercicio dos dois cargos. Vedou o art. 172 da Constituição Federal a acumulação de cargos publicos remunerados da União, dos Estados e dos Municipios; mas o paragrapho primeiro daquele mesmo artigo excetuou, expressamente "os cargos do magisterio e tecnico-cientificos, que poderão ser 
exercidos cumulativamente, ainda que por funcionarios administrativos, desde que haja compatibilidade dos horarios de serviço". Não estava ainda promulgada a Constituição quando foram nomeados os professores catedraticos do Curso de Doutorado, designados pela Congregação. Mas, ainda assim, a cumulação obedeceu ao futuro preceito constitucional.

Exatamente porque se cogitava de uma acumulação de cargos, o regulamento, no paragrapho unico do art. 14, bem claro deixou que "os vencimentos desses professores corresponderão a dois terços dos que lhes competirem como catedraticos do Curso de Bacharelado". Quanto, porém, aos que, não fossem designados e se submetessem a concurso, o art. 15 foi muito explicito no prescrever que lhes competirão "vencimentos integrais".

6. Que os professores catedraticos do Curso de Bacharelado, designados pela Congregação e nomeados pelo Governo para a regencia definitiva das cadeiras do Curso de Doutorado, eram e ficaram sendo professores catedraticos das em que foram investidos, parece intuitivo. Decorre do sistema e dos textos do dec. n. 6.429, de 9 de maio de 1934 .

Compõe-se o corpo docente da Faculdade de Direito da Universidade de São Paulo de professores catedraticos e docentes livres e, eventualmente, de professores contratados e de professores honorarios. Não havia, no regime do dec. n. 6.429, outra categoria de professores, qual dispunha o seu art. 44. Reproduziu-se aquele dispositivo, integralmente, no art. 41 do dec. 7.068, de 6 de abril de 1935.

Não podiam os professores catedracicos do Curso de Bacharelado, por certo, ser docentes livres do Curso de Doutorado. Nem para ele foram contratados, eventualmente. Nem entre os professores honorarios podiam contar-se. Designados pela Congregação, nomeou-os o Governo do Estado. Se se tratasse de simples designação transitoria, não havia necessidade da aprovação por dois terços de votos. Nem da nomeação governamental. Entre os professores 
catedraticos, portanto, tinham que ser classificados. Do outra fórma nem seria de mister o decreto de nomeação, essencial somente para os professores catedraticos.

7. Convem, neste passo, afim de encarar o assunto de frente, reler o topico do relatorio, que está á pag. 30 do fasciculo anterior desta revista:

"No capitulo em que trata dos professores catedraticos, define o decreto os que assim se qualificam e para os assim qualificados atribue as garantias de vitaliciedade $\mathrm{e}$ inamovibilidade (arts. 45-49).

"São catedraticos, prescreve o art. 45: 1.0) os nomeados por transferencia de igual disciplina de outra Faculdade de Direito oficial - o que não é o caso dos quatro professores; $2 .^{\circ}$ ) os nomeados independente de concurso, quando profissionais insignes, autores de obra doutrinaria de valor excecional ou notabilizados na especialidade - o que tambem não é o caso deles; $3 .^{\circ}$ ) os nomeados mediante concurso - o que ainda não vem ao caso, porque não fizeram concurso para essa nomeação; 4..$^{\circ}$ os nomeados para cadeira nova, que já tenham sido aprovados na Faculdade em concurso da materia dessa cadeira nova e hajam prestado serviços relevantes á Faculdade - o que tampouco é o caso deles.

“Como se vê, o decreto n. 6.429, nos termos e na vigencia do qual foram feitas as nomeações, não só não outorga aos nomeados a vitaliciedade, senão que lha nega expressamente, pois, afóra os casos. que não vêm a lanço, de professores transferidos ou insignes, somente confere esse atributo aos nomeados por concurso" 
Seria o argumento irresistivel se, no art. 45 citado, não se cogitasse apenas dos professores do Curso de Bacharelado, somente aos quais se referiu.

8. Do provimento das cadeiras do Curso de Doutorado cogitou o art. 14 do dec. n. 6.429, de 9 de maio de 1934. Nele se consignou, em verdade, disposição de carater transitorio, para que ficasse o professorado daquele Curso, desde logo constituido. Tanto assim foi que, no dec. n. 7.068, de 6 de abril de 1935, ora vigente, aquele texto teve outro conteudo:

"Art. 14. 0 ano letivo, o regime de frequencia, a taxa de matricula, as inscrições para exame, a fórma de provimento das cadeiras e, salvo o disposto no artigo anterior, os vencimentos são, no Curso de Doutorado, iguais aos do Curso de Bacharelado".

Omitiu o novo regulamento a fórma de provimento de que cogitara o art. 14 do dec. n. 6.429: o da designação dos proprios professores catedraticos do Curso de Bacharelado, por dois terços de votos da Congregação. Omitindo-a, ressalvou, porém, e expressamente, os professores nomeados naquelas condições, referindo-se ao artigo anterior, que é este:

“Art. 13. Pela regencia de cadeira no Curso de Doutorado competem ao professor, que seja catedratico no de Bacharelado, vencimentos correspondentes a dois terços dos que lhe cabem nesta ultima qualidade"

Quer isto dizer:

a) que, no regime do dec. n. 6.429 , de 9 de maio de 1934, nas cadeiras do Curso de Doutorado, que se achassem vagas, seriam providos professores catedraticos do Curso de Bacharelado, que a Congregação, por dois terços de votos, 
designasse; ou, então, se isso não acontecesse, os que se submetessem a concurso, na fórma dos arts. 66 e seguintes;

b) que, no regime do dec. n. 7.068 , de 6 de abril de 1935, as cadeiras do Curso de Doutorado serão providas na fórma por que se dá o provimento das cadeiras do Curso de Bacharelado.

Desapareceu, desse geito, o provimento por designação da Congregação, por dois terços de votos; mas ficaram os professores catedraticos, nomeados, no regime do dec. n. 6.429, para o Curso de Doutorado, investidos dos mesmos direitos que os providos no regime do dec. n. 7.068 , inclusivé o da vitaliciedade e o da inamovibilidade.

9. Entre as condições, a que se subordinou a transferencia da Faculdade de Direito de São Paulo ao Estado de São Paulo, incluiu o dec n. 24.102, de 10 de abril de 1934, expressamente:

a) a da garantia, pelo Governo Federal, aos professores e funcionarios, até então nomeados, dos direitos e vantagens que as leis federais lhes asseguram, inclusivé o pagamento dos respectivos vencimentos pelo Tesouro Federal, sem embargo de outros direitos que as leis estaduais outorguem a professores e funcionarios de igual categoria;

b) a de terem os profesores e funcionarios, nomeados posteriormente áquele decreto, os seus direitos e deveres regulados pelas leis estaduais.

São os profesores catedraticos do Curso de Bacharelado, nomeados, depois daquele decreto, para o Curso de Doutorado, ao mesmo tempo, funcionarios publicos federais e funcionarios publicos estaduais: federais como professores do Curso de Bacharelado; estaduais, como professores do Curso de Doutorado.

10. No concernente ao caso do Professor Waidemar Ferreira, está ele resolvido pelo não recebimento de seus vencimentos no interregno das sessões legislativas de 1935 
a 1936. E pelo protesto de ressalva de seus direitos futuros, se o Curso de Doutorado vier a restaurar-se.

11. Professor catedratico da cadeira de Economia Politica e Ciencia das Finanças, do Curso de Bacharelado, não podia o Professor J. J. Cardozo de Mello Neto deixar de ser designado, pela Congregação, para a regencia da cadeira de Ciencia das Finanças, do Curso de Doutorado. Bem andou ela no designa-lo. Andou bem o Governo do Estado do nomea-lo. Era o mais indicado para a investidura. A nova cadeira fazia parte da que ele conquistara em concurso.

Em face das leis, a que a Faculdade de Direito está sujeita, era ele professor federal da cadeira de Economia Politica e Ciencia das Finanças, do Curso de Bacharelado, e professor estadual da cadeira de Ciencia das Finanças, do Curso de Doutorado, ao promulgar-se a lei n. 114, de 11 de novembro de 1935, que tornou facultativa a existencia do Curso de Doutorado.

Acontece, porém, que aquela lei desdobrou a cadeira de Economia Politica e Ciencia das Finanças, nestes termos:

"Art. 4. A cadeira de Ciencia das Finanças passará da segunda secção do segundo ano do Curso de Doutorado para o segundo ano do Curso de Bacharelado.

“6

"Paragr. 2. A cadeira de Economia Politica e Ciencia das Finanças, do primeiro ano do Curso de Bacharelado, ficará denominada: cadeira de Economia Politica"

Mercê deste dispositivo legal, o professor federal J. J. Cardozo de Mello Neto ficou sendo o catedratico da cadeira de Economia Politica, do primeiro ano do Curso de Bacharelado. Como, entretanto, era ele, de outro lado, o professor estadual da cadeira de Ciencia das Finanças, do Curso de Doutorado, que passou para o segundo ano do 
Curso de Bacharelado, ficou ele, sem duvida nenhuma, a lecionar as duas cadeiras, de que era e é titular, no Curso do Bacharelado, não por deliberação propria, mas por força de lei. Foi esta que criou a situação imprevista por ele, mas em que se encontra, de ser professor catedratico de duas cadeiras do Curso do Bacharelado.

12. Não ha, nessa circunstancia, o menor vislumbre de ilegitimidade. Que era, e ainda é, possivel ao professor catedratico do Curso de Bacharelado vir a ser professor catedratico do Curso de Doutorado, não ha contestar. Permite-o a lei federal. Permite-o a lei estadual. Um professor póde, sem deslustre, com inteira dignidade, ser catedratico de duas cadeiras na mesma Faculdade, uma no Curso de Bacharelado e outro no Curso de Doutorado. $\mathrm{E}$ bem pode suceder, como sucedeu, que a lei reuna as duas cadeiras num só curso. Não tem fóros de cidade o argumento de que, em cento e dez anos de vida da Faculdade de Direito, nunca se verificou a hipotese de um só professor ser catedratico de duas disciplinas. Só depois de cem anos foi que se criou o Curso de Doutorado; e foi da suspensão posterior deste que resultou a situação, que nos cem anos anteriores se não podia imaginar. Não se apresentou ela por vontade do professor, mas adveiu da lei, de maneira que somente por maledicencia seria licito arguir o proposito de converte-la "em monopolio e meio de ganhar dinheiro"

13. Discutiu-se se, perante o novo estado de cousas, deveria ser considerada vaga a cadeira de Ciencia das Finanças, transferida do Curso de Doutorado para o Curso de Bacharelado. Afim de evitar controversia, formulou o Professor A. dE Sampaio Doria uma proposta, em Congregação, para que se nomeasse uma comissão de professores, que estudasse o assunto e emitisse parecer. Aceita a proposta, ficou a comissão constituida dos Professores Drs. Mario MAsagão, Ernesto de Moraes Leme e Alexandre Correia. Apresentaram eles parecer, pelo primeiro redigido, em Congre- 
gação de 1 de outubro de 1936, de que se transcreve esta conclusão :

“A lei estadual n. 6.429, de 9 de maio de 1934, dispondo sobre o provimento das cadeiras do Curso de Doutorado, declarou, no art. 14, que para elas seriam nomeados os proprios professores do Curso de Bacharelado, que a Congregação indicasse, por dois terços de votos.

"A Congregação indicou varios professores para aquelas investiduras, como os Drs. GaMa Cerqueira, Cardozo de Mello Neto, A. de Sampaio Doria, Waldemar Ferreira e Vicente Ráo.

"Na conformidade da lei estadual, esse professores foram nomeados catedraticos do Curso de Doutorado e entraram em exercicio, sendo que, em relação á cadeira de Ciencia das Finanças, se deu o provimento do Professor Cardozo de Mello Neto.

"Essa cadeira, transferida do Curso de Doutorado para o de Bacharelado, está, pois, devidamente provida, nada havendo que providenciar quanto ao concurso referido na proposta".

Presidia á Congregação o Director da Faculdade de Direito, o Professor Dr. Francisco Morato. Tomando conhecimento do parecer referido, ela o aprovou, por unanimidade de votos, em escrutinio secreto.

14. Decretou-se e promulgou-se, em 9 de julho de 1935, a Constituição do Estado de São Paulo. Estavam os professores do Curso de Doutorado, da Faculdade de Direito, a esse tempo, no exercicio de seus cargos. Admitindo, mas não concedendo, devessem eles, para como catedraticos ser havidos, ter-se submetido a concurso de provas e de titulos, ainda assim se lhes não pode negar as vantagens de seus cargos, por efeito do disposto no art. 6 das disposições tran- 
sitorias daquela Constituição. "As garantias", nele se preceitua, "as garantias outorgadas nesta Constituição aos funcionarios, cuja primeira investidura é sujeita a condições especiais, estendem-se aos que estiverem providos efetivamente em tais cargos, ao ser esta promulgada".

Tendo sido os professores catedraticos do Curso de Doutorado efetivamente providos, por decreto do Governo do Estado, gozam eles de todas as garantias aos seus cargos ineerentes, ainda que, para isso, devessem de submeter-se a concurso.

Parece diafano como a luz solar.

São Paulo, 29 de agosto de 1937. 